\title{
Reference and edification of traditional culture on art design innovation Yejun $\mathrm{Fu}$

\author{
Southwest Minzu University, Chengdu Sichuan, 610041, China
}

Keyword: Traditional culture, Art, Design, Innovation, Reference, Edification.

\begin{abstract}
Chinese traditional culture as characteristic Chinese culture formed by five thousand years' historical and cultural accumulation has been regarded as important referential resource in art work creation due to its abundant cultural connotation and national features, thus has profound enlightening influence on art design ${ }^{[1]}$. But reference does not mean to imitate traditional culture completely but to absorb the quintessence and connotation and discard dregs, which requires for artists to clarify the important value of traditional culture when referring to traditional culture during art design innovation and correctly know the development situation of art design, so as to truly go deep to profoundly explore the influential value of traditional culture in art design. This article has made detailed analysis on the reference and edification of traditional culture on art design innovation, aiming at provide theoretical reference for promoting good development of traditional culture and art design.
\end{abstract}

\section{Introduction}

Chinese traditional culture is the ideology and culture formed by historical accumulation and consciousness development in five thousand years' history of Chinese nationality which has reflected the development course of history and culture of Chinese nation but also contained deep level of artistic and cultural connotation. This has made Chinese traditional culture has been imitated by artists in the process of artwork creation so as to produce a lot of excellent artworks containing Chinese traditional culture. But under the impact of current international art concept, many artists start focus their attention of creation material collection to exterior culture and gradually ignore the inheritance and imitation from traditional culture. Occurrence of the phenomenon has made China's art design work lose national characteristics on one side and will result into stagnation of traditional culture inheritance $^{[2]}$. Thus, China's art design should focus on studying how to imitate traditional culture for innovation and get enlightened truly so as to realize art design innovation and develop China's traditional culture.

\section{Important value of traditional culture}

Traditional culture is national cultural consciousness formed, evolved, deposited and kept in a nation's historical progress which can reflect its national character and features, style and features but can also influence the nation's physical spirit and cultural consciousness as an important characteristic to explain national spirit and distinguish national features ${ }^{[3]}$. Traditional culture is mainly constituted by two forms: spiritual and material. The material aspect is mainly reflected in architecture, clothing, etc., and spiritual aspect is reflected in the ideology, customs and morality. Because traditional culture contains a nation's unique characteristic which plays a unarguably promoting effect for highlighting national features, under the trend of global integration, developing and inheriting national traditional culture will have positive impact on national development.

\section{Development status of China's art design}

Art design is a creation process in which designers use their own aesthetic concepts or manifestation technique to visualize their conceptions or plans in their own subjective consciousness. With the improvement of people's living standard, people starts focusing on their spiritual and artistic 
edification and enjoyment, which has indirectly promoted the development of art design and there emerge phenomena that every walk of life is penetrated with art design concepts. In the environment that China's modern art design is in line with international design concepts, art design and similar art creation forms start setting international art concepts as creative referential materials, which has become a new tide of current art innovation ${ }^{[4]}$. But we can know by analyzing and thinking on this phenomena that this will lead to the internationalization of art design until it loses national unique features. This will make artwork lose certain differentiation for its features, but also go against with developing China's traditional culture not in accordance with the concept of developing and inheriting traditional culture in every industry.

\section{Influence value of China's traditional culture on art design}

\section{Provide abundant design materials}

In the process of art design, material hunting is the important beginning to carry out relevant work. In different countries and nations, traditional culture is regarded as the important source for designers' art design material supply. It is even more so in China's traditional culture because China is an ancient country with five thousand years' history. In five thousand years' cultural accumulation, language, words, thinking and customs have evolved into national features and extensive and profound traditional culture. This means that extremely abundant materials can be found in China's traditional culture and this process can also provide powerful cultural and spiritual support for broaden designers' creation space and creation thinking.

\section{Expand art design thinking}

As divergent design thinking determines the feasibility and quality of artwork innovation during the process of art design innovation, most art designers pay great attention to explore how to form and practice their own divergent thinking. Through thousand years' accumulation in China's traditional culture, there exist some relations between different spirits showing supplementary characteristic culture, embodying distinctive cultural form, and forming colorful cultural breadth. So art designers can correctly grasp features of China's national traditional culture with generally same cultural concept, but can expand their own design thinking with rich cultural forms. Then they can constantly expand their own cultural cognition scope in the process of deeply understanding traditional culture to stimulate their own innovative thinking and promote their creativity significantly.

\section{Promote art design reform}

Artwork as a free, abundant and innovative ideological manifestation form is not just limited to one or several expression forms in the development process. Art can always walk in the front of time development and lead people's art awareness to form and develop with constant breakthrough, innovation and reform on human beings' thoughts and cognitions. Innovation and reform do not mean to completely lose contact with reality but to change and add new ideologies on the basis of previous correct consciousness. In art design reform, traditional culture can promote designers to obtain new thoughts and provide object consciousness from different angles. On the other hand, traditional culture is the critical basis for art design. Only on the basis of correct understanding and basic aesthetic concept of traditional culture, designers can process and innovate their own thoughts, which means traditional culture has significant impact on art design reform. Relevant designers should understand the important influencing effect and make use of it voluntarily.

\section{Reference of traditional culture for art design}

\section{Refer to traditional culture for creating artistic conception}

Art design as an art form manifested by designers through visualizing their own subjective consciousness has the characteristic of containing extremely strong subjective consciousness in the 
artwork which is an important method for viewers to understand designer's own emotions and expressive concepts. In the process of using art design work to express design concepts, artistic conception is the punchline of the artwork and the important embodiment of artwork soul influencing the overall design level of artwork expression and endowing the artwork with richer connotation. Traditional culture as the consciousness carrier of accumulation in long-lasting days contains cultural deposits of extremely important referential significance for art design innovation. Reference of traditional culture can effectively enrich artwork meaning and learn how to create unique conception from it. For example, in art design innovation, referring to space painting technique and expression methods in Chinese traditional landscape paintings in the process of art design can help learn how to highlight the extraordinary refined and natural conception by depicting landscape so as to flexibly apply to their own artworks for effectively improving their own design level and intensify the artwork expression level.

\section{Refer to traditional culture for design inspiration stimulation}

In the process of art design innovation, designer's proficiency is important but design inspiration is the key element influencing the overall soul and implication of artwork, which means that designers must seek and stimulate their own good design inspiration in the innovation process. But as an invisible and untouchable awareness, inspiration requires for designers exposed in objects with good consciousness according to their own design direction. China's traditional culture is broad and profound good in cultural width and depth which has created more sensory things for art designers and promote their design inspiration stimulation. For example, designers can browse poetry verses, historical paintings, traditional music and other traditional cultural carriers during art design innovation to stimulate their own artistic awareness through the abundant artistic connotation in these artworks for improving the possibility of inspiration sparkling in art design. Meanwhile, under the edification of traditional culture, designers will be influenced unconsciously in their design style so as to form design characteristics with national distinction.

\section{Refer to traditional culture for characteristic artwork creation}

Under the rapid development of information era, information transmission becomes easier, and it shows a friendly exchange prospect of mutual influence and reference in culture, customs and ideology in different countries. But as China's traditional culture is formed with extremely strong national features by inheritance in generations, relevant artworks have conquered friends in the world with traditional aesthetics, profound cultural deposit and abundant cultural forms, thus a characteristic "China style" has formed and taken an important position in world art. Thus, art designers need absorb excellent culture in artwork innovation but also realize the important status and good awareness in China's traditional culture, clarify correct creative consciousness of referring to traditional culture for shaping their own artwork features and developing Chinese culture so as to create brilliant artworks with high artistic level and deeper artistic conception. For example, blue and white porcelain and Qipao are Chinese characteristic work enjoying great reputation in the world, so designers can properly integrate art elements of this type so as to create artworks with unique national features and high identification.

\section{Enlightenment of traditional for art design}

\section{Positively develop excellent traditional culture}

Traditional culture is culture consciousness and spirit formed and accumulated in historical development and evolution during which a lot of splendid culture consciousness have been inherited but some decayed and bad traditional culture consciousness have spread up to now. We need to clarify in this process that reference of traditional culture does not mean to limit design consciousness to using traditional culture for art creation but to set traditional culture as punchline or supplement on the basis of combining designers' own concept and modern art design concept. This can help design 
artworks in line with modern aesthetic concepts, in pace of time spirit, containing rich cultural deposits and presenting national features, so as to provide creation assistance for promoting modern art development and developing China's traditional culture.

\section{Pay attention to combine with diversified foreign culture}

In the process of art design innovation, innovation is the key concept for artwork creation. In the process of modern art design, referring to traditional culture can endow artworks with deeper meaning and effectively improve artwork's artistic level. Artworks as an art form integrating multiple thinking and culture can only progress by positively absorbing excellent foreign culture and consciousness in its development process. Thus, art design requires to positively referring to China's traditional culture but to promote artwork to develop to the glob by combining with diversified foreign culture. In this process, traditional culture can be used to effectively highlight Chinese national features providing good foundation for the artwork going to glob and developing national spirit.

\section{Focus on carrying out traditional culture education}

Currently as China is getting powerful day by day, Chinese excellent culture and thinking have been perceived objectively during friendly communication with other countries so that China's traditional culture is well received by friends in the world. But it can be seen in the environment when various foreign culture flowing into China that traditional culture education and popularization have been weakened, which is bad for the inheritance of China's traditional culture and makes for art design innovation blindly pursuit of being international without a correct understanding of the important of referring to traditional culture. Thus, to guarantee that China's art design works can truly highlight national culture and develop national spirit, we should start from traditional culture education so as to strengthen designers' ability of perceiving traditional culture aesthetics and improve their understanding of traditional cultural connotation so as to make them become excellent design talents with good modern art and abundant traditional cultural connotation. This requires to pay attention to the guidance of modern art design concept in elementary education and intensify the publicity education of traditional culture, but also requires for designers to voluntarily understand the history of Chinese nation, constantly absorb rich traditional cultural connotation so as to substantially improve their own art design innovation ability.

\section{Conclusion}

To sum up, in the process of time progress and development, the transition of artistic concept is inevitable. But during the art design innovation, it is necessary to focus on absorbing foreign culture, creating excellent works with time characteristics, and also to correctly realize the influence value of traditional culture on art design innovation, and actively explore effective methods for referring to traditional culture and deeply think about enlightening thoughts of traditional culture, to guarantee truly absorbing fine essence of traditional culture in the process for creating brilliant art design works, and pay attention to the development, promotion and inheritance of traditional culture under the influence of thinking inspiration, for the purpose of effectively providing broad thinking creative space for art design and substantially improve art designers' creation level and develop the artistic value of traditional culture.

\section{Acknowledgement}

2016 central colleges and universities basic research special fund project (project No. 2016SZYQN59). 


\section{References}

[1] Zhou Yuxun. Reference and inspiration of traditional culture for art design, Art Education, 2014 (12):274.

[2] Xie Li. Reference and revelation of China's traditional culture for art design innovation, Modern Communication, 2015 (12): 73.

[3] Wu Xiaohong. Inheritance and innovation of China's traditional culture in art design, Comprehensive Digest, 2015 (09): 58.

[4] Xu Yunchun. Innovative application of China's traditional cultural elements in school art education, Research of Modern Basic Education, 2014 (01): 43-48. 